\title{
Surface Photografting Polymerization of Binary Monomers Maleic Anhydride and $n$-Butyl Vinyl Ether on Polypropylene Film I. Effects of Principal Factors
}

\author{
Chang-Min XING, ${ }^{*, * *}$ Jian-Ping DeNG, ${ }^{*, * *}$ and Wan-Tai YANG ${ }^{*, * * \dagger}$ \\ *Department of Polymer Science, Beijing University of Chemical Technology, Beijing 100029, China \\ ${ }^{* *}$ Key Laboratory of Science and Technology of Controllable Chemical Reactions, \\ Ministry of Education, Beijing 100029, China
}

(Received April 22, 2002; Accepted August 27, 2002)

\begin{abstract}
Maleic anhydride (MAH) was grafted onto polypropylene (PP) film efficiently by means of introducing the electron donor monomer $n$-butyl vinyl ether (n-BVE), under UV irradiation. The principal factors affecting surface photografting polymerization such as irradiation time, molar ratio of MAH to BVE, monomer concentration, photoinitiators, UV and solvents, were investigated systematically. The results show that the photografting of MAH/BVE is an effective approach to modify the surface property of the polymeric materials, and the photografting process is very efficient. The contact angle of the grafted surface against water could decrease from $87^{\circ}$ to less than $20^{\circ}$ within $40 \mathrm{~s}$ of the irradiation time. The grafting efficiency would reach the highest when the molar ratio of MAH to BVE was 1:1, which indicated that the formation of charge transfer complex (CTC) between the binary monomers was favorable to the photografting polymerization. Among the photoinitiators benzildimethylketal (BDK), benzophenone (BP) and isopropylthioxanthone (ITX), the sequence of grafting efficiency was BP $>$ ITX $>$ BDK. Far UV $(200-300 \mathrm{~nm})$ radiation played a decisive role in the photografting polymerization and high UV intensity could accelerate this process. The solvent with good affinity towards the substrates was favorable to increase the grafting efficiency, because the diffusion of monomer and photoinitiator to the liquid-solid interface could be swimmingly. FT-IR spectra confirmed that both MAH and BVE had been successfully grafted onto PP film.

KEY WORDS Surface Modification / Photografting Polymerization / Maleic Anhydride / $n$-Butyl Vinyl Ether / Charge Transfer Complex /
\end{abstract}

Up to now, grafting copolymerization has been a common method to modify and improve the properties of the polymeric materials. There are many approaches to initiate the grafting copolymerization, including electronic beam, ${ }^{1} \gamma$-ray, plasma, ${ }^{2} \mathrm{UV}$, shear force, ${ }^{3}$ etc. Among those, grafting copolymerization initiated by UV has remarkable advantages in surface modification of polymeric materials, especially polyolefin, because the photografting polymerization takes place mainly on the surface or subsurface, without damaging the bulk property.

In the past few decades, many researchers have done much in the photografting polymerization field from various aspects. With regard to the operation method, there have been vapor phase system, ${ }^{4,5}$ liquid phase system $^{6}$ and continuous operation system ${ }^{7}$ in the previous reports. As to the factors affecting the photografting polymerization, the effects of $\mathrm{UV},{ }^{8}$ photoinitiators, ${ }^{9}$ solvents, ${ }^{10}$ etc., have been reported in detail. In addition, some reports involved the structure and morphology of the surface of the grafted materials. ${ }^{11-13}$

Concerning the monomers for photografting, the vinyl monomers ${ }^{14-16}$ are popularly used, such as acrylic acid (AA), methacrylic acid (MAA), methyl methacrylate (MMA), styrene (St), acrylamide (AM), acrylonitrile (AN), vinyl acetate (VAc), etc. In order to make the materials possess special properties, some monomers with functional groups were introduced, ${ }^{17,18}$ such as glycidyl acrylate (GA), glycidyl methacrylate (GMA), $N$-vinyl pyrrolidone (NVP), etc. Maleic anhydride (MAH), however, was seldom used in photografting, ${ }^{19}$ although it is widely used in the solution grafting and melting grafting. In fact, MAH used as a monomer for photografting has much advantages: 1) The anhydride group in MAH molecule has comparatively strong polarity and it can be hydrolyzed into two carboxyl groups, which will increase the density of polar groups on the surface of the grafted polymer, and therefore the surface hydrophilicity can be improved effectively. 2) The anhydride group can undergo a number of reactions with other functional groups due to its high activity, which will make the grafted polymer a potential functional material.

Recently, we have reported in one of our previous papers that MAH itself could perform photografting polymerization, but the efficiency was low. ${ }^{19}$ The results showed that only when the irradiation time was prolonged to 3 min did the grafting efficiency reach $60 \%$.

${ }^{\dagger}$ To whom correspondence should be addressed (Tel: +86-10-64432262, Fax: +86-10-64416338, E-mail: yangwt@mail.buct.edu.cn). 
This is because MAH is difficult to homopolymerize under usual conditions due to the great steric hindrance, as commonly considered, which leads to the difficulty of the grafting chain propagation. Fortunately, $\mathrm{H}$. Kubota and Y. Ogiwara et al. ${ }^{20,21}$ have pointed out that the monomers difficult to/cannot be grafted will undergo photografting smoothly by means of introducing the suitable comonomer. Given that the electron donor monomer $n$-butyl vinyl ether ( $n$-BVE) can form charge transfer complex (CTC) ${ }^{22}$ with MAH and consequently they tend to undergo alternating copolymerization, which was expected to bring favorable effect on photografting polymerization, we designed the photografting polymerization system of binary monomers MAH/BVE and carried out the study systematically.

\section{Experimental}

\section{Materials}

Commercial casting polypropylene (CPP) film, $30 \mu \mathrm{m}$ thick, with transmittance close to $100 \%$ for UV radiation (200-400 $\mathrm{nm}$ ), was used as the substrate, which was first cut into circular shape of about $50 \mathrm{~mm}$ in diameter and then subjected to Soxhlet extraction with acetone for $24 \mathrm{~h}$ to remove the additives and impurities.

Maleic anhydride (MAH) was purified by distillation before use, and $n$-butyl vinyl ether ( $n$-BVE) was analytical grade, used without further purification. The photoinitiators benzildimethylketal (BDK), benzophenone (BP) and isopropylthioxanthone (ITX), were analytical grade, used without further purification. The solvent acetone (AC), ethyl acetate (EA), tetrahydrofuran (THF), dimethylformamide (DMF), were analytical grade, used without further purification.

\section{Photografting Polymerization Procedure}

The photografting polymerization was carried out in the apparatus the same as that in the previous pa-

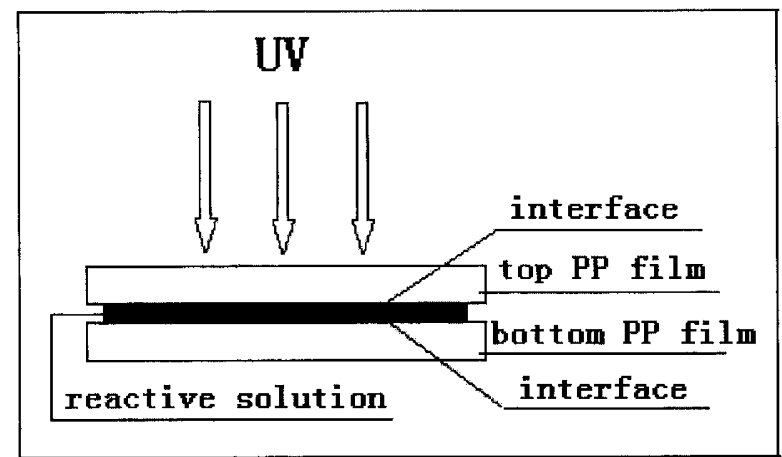

Figure 1. Profile of the assembly for photografting polymerization. pers, ${ }^{19,23}$ which was built in our laboratory. The assembly for photografting polymerization is shown schematically in Figure 1, which is named "Film Interface Photopolymerization (FIP)" technique ${ }^{9}$ used in our photografting operation.

A certain amount of solution (about $5 \mu \mathrm{L}$ ) containing monomer and photoinitiator was deposited between two overlapping films with a microsyringe and spread into an even and thin liquid layer (about $3 \mu \mathrm{m}$ thick) with proper pressure. Then the assembly was laid on a plate and covered with a piece of quartz glass. The assembled unit was irradiated by UV radiation (highpressure mercury lamp, $1 \mathrm{~kW}$, the distance from the lamp to the sample could be varied) from the top side. The temperature was controlled by a thermocouple and the extent of photografting polymerization was controlled by varying the irradiation time. After irradiation, the top and bottom films were separated and put into the vacuum oven to vaporize the residual monomer and solvent, then Soxhlet-extracted with acetone for $8 \mathrm{~h}$ to remove the homopolymer (in fact, the ungrafted polymer in this system is copolymer, but we still call it homopolymer by convention, et seq.).

The photografting polymerization parameters, grafting yield $\left(Y_{\mathrm{g}}\right)$, percent conversion of monomer to the overall plolymerization $\left(C_{\mathrm{p}}\right)$, percent conversion of monomer to the grafting plolymerization $\left(C_{\mathrm{g}}\right)$, grafting efficiency $\left(E_{\mathrm{g}}\right)$, were obtained by the gravimetric method according to the following definitions:

$$
\begin{aligned}
& Y_{\mathrm{g}}=\left(W_{\mathrm{g}} / W_{\mathrm{f}}\right) \times 100 \% \\
& C_{\mathrm{p}}=\left(W_{\mathrm{p}} / W_{\mathrm{m}}\right) \times 100 \% \\
& C_{\mathrm{g}}=\left(W_{\mathrm{g}} / W_{\mathrm{m}}\right) \times 100 \% \\
& E_{\mathrm{g}}=\left(W_{\mathrm{g}} / W_{\mathrm{p}}\right) \times 100 \%
\end{aligned}
$$

where $W_{\mathrm{f}}$ is the weight of the two blank films; $W_{\mathrm{m}}$ is the weight of the monomer between the two films; $W_{\mathrm{p}}$ is the weight of the polymer produced, including homopolymer and grafted polymer, which was obtained by weighing the films after vaporizing the residual monomer and solvent; $W_{\mathrm{g}}$ is the weight of the grafted polymer, which was obtained by weighing the films after extracting the homopolymer.

\section{FT-IR Spectra}

The IR spectrum of the grafted film PP-gMAH/BVE, which had been Soxhlet-extracted with acetone for $8 \mathrm{~h}$ to remove the homopolymer, was measured by Fourier transform infrared spectrometer (Nicolet-60 SXB, Northvale, NJ). Moreover, the FT-IR spectrum of the blank film was also measured as reference under the same conditions. 
Table I. Performance of the photografting polymerization of MAH/BVE on PP*

\begin{tabular}{ccccccc}
\hline$[\mathrm{M}] /[\mathrm{B}]^{\mathrm{a}}$ & $t(\mathrm{sec})^{\mathrm{b}}$ & $Y_{\mathrm{g}}(\%)$ & $\theta\left(^{\circ}\right)^{\mathrm{c}}$ & $C_{\mathrm{p}}(\%)$ & $C_{\mathrm{g}}(\%)$ & $E_{\mathrm{g}}(\%)$ \\
\hline $0 / 4^{\mathrm{d}}$ & 60 & 0 & 87 & 0 & 0 & 0 \\
$1 / 4$ & 60 & 0.17 & 72 & 33.8 & 8.7 & 25.7 \\
$2 / 3$ & 60 & 0.51 & 49 & 68.5 & 25.7 & 37.5 \\
$1 / 1$ & 60 & 1.35 & 15 & 86.9 & 68.2 & 78.5 \\
$3 / 2$ & 60 & 1.13 & 16 & 83.6 & 56.9 & 68.1 \\
$4 / 1$ & 60 & 0.42 & 45 & 52.4 & 21.3 & 40.6 \\
$4 / 0^{\mathrm{e}}$ & 60 & 0.19 & 68 & 27.9 & 9.7 & 34.8 \\
& & & & & & \\
$1 / 1$ & 5 & 0.36 & 63 & 28.3 & 18.2 & 64.3 \\
$1 / 1$ & 10 & 0.59 & 44 & 40.6 & 28.3 & 69.7 \\
$1 / 1$ & 15 & 0.72 & 30 & 51.0 & 36.4 & 71.4 \\
$1 / 1$ & 20 & 0.87 & 24 & 59.4 & 43.9 & 73.9 \\
$1 / 1$ & 40 & 1.16 & 17 & 78.3 & 58.6 & 74.8 \\
$1 / 1$ & 60 & 1.35 & 15 & 86.9 & 68.2 & 78.5 \\
\hline
\end{tabular}

*Photoinitiator, BP, $0.05 \mathrm{~mol} \mathrm{~L}^{-1}$; solvent, acetone; volume of reaction solution, $5 \mu \mathrm{L}$; reaction temperature, $60^{\circ}$; UV intensity, $7600 \mu \mathrm{W} \mathrm{cm} \mathrm{cm}^{-2}$

${ }^{a}$ Molar ratio of MAH to BVE, the total concentration is $4 \mathrm{~mol} \mathrm{~L}^{-1}$.

${ }^{b}$ Irradiation time. ${ }^{\mathrm{c}}$ Contact angle against water, anhydride groups had been hydrolyzed. ${ }^{\mathrm{d}}$ Content of MAH is $0 .{ }^{\mathrm{e}}$ Content of BVE is 0 .

\section{Contact Angle Against Water}

The grafted films were immersed in the sodium hydroxide solution $(5 \mathrm{wt} \%)$ for about $10 \mathrm{~min}$ at $25^{\circ} \mathrm{C}$, so as to hydrolyze the anhydride groups into carboxyl groups. Then the contact angle of the grafted surface against water was measured on a JJ-I contact angle measuring instrument (Changchun Optical Instrument Plant, China). To each sample with various grafting yields, the measurements were carried out repeatedly at various spots and afterwards the average was calculated. In addition, the contact angles of the grafted films without being hydrolyzed were also measured as reference under the same conditions.

\section{RESULTS AND DISCUSSION}

\section{Performance of the Photografting Polymerization of $M A H / B V E$}

In the first stage of this study, a series of experiments were carried out by varying the molar ratio of MAH to BVE while keeping the irradiation time $60 \mathrm{~s}$, then the evolution of the photografting polymerization was investigated under the condition that the ratio of MAH to BVE was kept 1:1. The experimental results were summarized in Table I.

It can be obviously seen from Table I that the grafting efficiency reached the highest and the modification effectivity was the best when the monomer feed ratio of MAH to BVE was 1:1, which indicated that the above assumption was reasonable. That is, since $\mathrm{MAH}$ and BVE can form charge transfer complex (CTC) ${ }^{22}$, they are prone to undergo alternating copolymerization, thus resulting in the smooth grafting chain propagation. To speak in detail, the grafting yield $\left(Y_{\mathrm{g}}\right)$ reached $1.35 \%$ and the grafting efficiency $\left(E_{\mathrm{g}}\right)$ was nearly $80 \%$, more- over, the contact angle against water decreased to less than $20^{\circ}$. The detailed mechanism of CTC will be presented in the latter article. In addition, it is also found from Table I that BVE itself could not undergo polymerization because BVE is a typical monomer for cationic polymerization, while MAH itself could undergo polymerization to some degree, which was consistent with our previous result. ${ }^{19}$

With regard to the photografting evolution, the reaction rate is very high. Also from Table $\mathrm{I}, Y_{\mathrm{g}}, C_{\mathrm{p}}$, and $C_{\mathrm{g}}$ all increased smoothly and rapidly along with the irradiation time. For example, the grafting yield reached more than $1 \%$ and nearly $80 \%$ of the monomer had performed plolymerization in the preceding $40 \mathrm{~s}$. Later, the reaction rate slowed down and the photografting polymerization was nearly over within $60 \mathrm{~s}$.

From the results demonstrated above, it can be concluded that the photografting of MAH/BVE is a novel rapid effective approach to modify the surface property, which may be applicable to the industrial field in the surface modification of the commercial polymeric materials.

\section{Principal Factors Affecting the Photografting Polymer- ization}

Photoinitiators. To the surface photografting polymerization, the primary requirement is to generate the surface free radicals on the substrate, so it is essential to investigate the effects of photoinitiators. In this study, three photoinitiators of different types, benzildimethylketal (BDK), benzophenone (BP) and isopropylthioxanthone (ITX) were examined and the results are shown in Figure 2.

As to $C_{\mathrm{p}}$, it can be found from Figure 2 that the sequence of these three photoinitiators was $\mathrm{BDK}>\mathrm{ITX}>\mathrm{BP}$, and as to $Y_{\mathrm{g}}$, the sequence was $\mathrm{BP}>\mathrm{ITX}>\mathrm{BDK}$. This means that BDK has the highest polymerization ability while the lowest grafting ability; on the contrary, BP has a little lower polymerization ability while the highest grafting ability; and ITX is between them. Obviously, BP is the most efficient photoinitiator for the photografting polymerization. The initiation mechanisms of these three photoinitiators are presented as follows.

As to BDK, it is a typical Norrish I type photoinitiator ( $\alpha$-cleavage) ${ }^{24}$ widely used in the photocuring industry. Under UV irradiation, BDK undergoes the reaction expressed in the following equation:

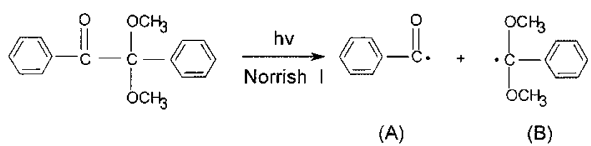

Because the free radicals (A) were so active that most of the monomer around them performed homopolymer- 


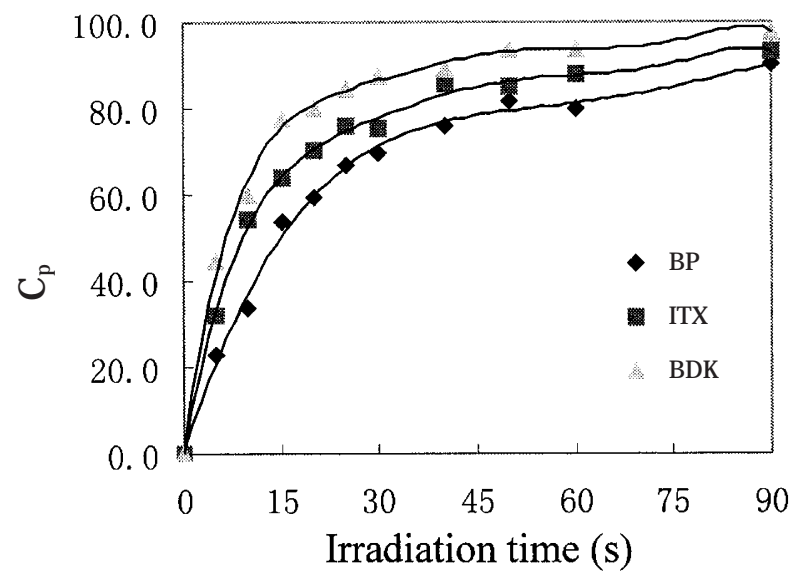

(A)

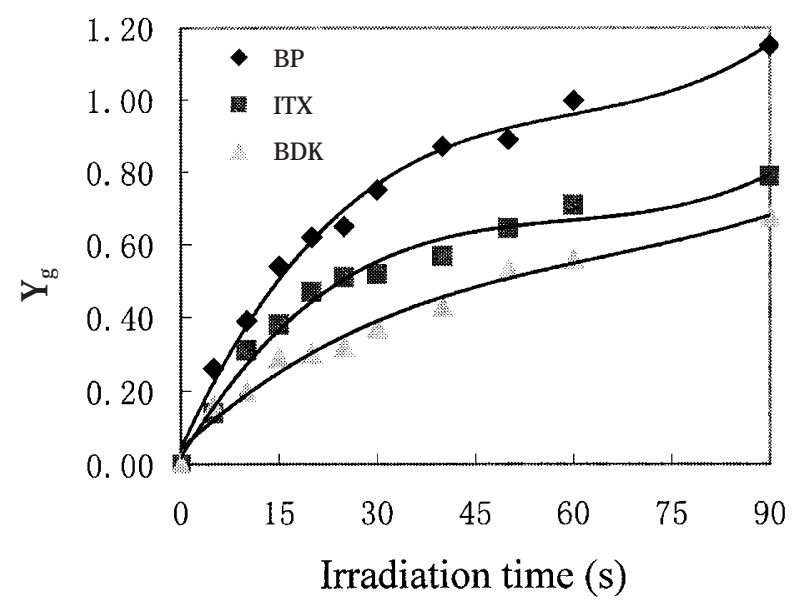

(B)

Figure 2. Effects of various photoinitiators on overall polymerization (A) and graft polymerization (B) of MAH/BVE. Molar ratio of MAH to BVE, $1: 1$; total monomer concentration, $4 \mathrm{~mol} \mathrm{~L}^{-1}$; concentration of photoinitiator, $0.05 \mathrm{~mol} \mathrm{~L}^{-1}$; solvent, acetone; volume of reaction solution, $5 \mu \mathrm{L}$; reaction temperature, $60^{\circ} \mathrm{C}$; UV intensity, $8000 \mu \mathrm{W} \mathrm{cm}^{-2}$.

ization, the grafting polymerization was severely inhibited, resulting in the lowest grafting yield.

With respect to BP, it is a typical hydrogen abstractable photoinitiator popularly used in the photografting and photocross-linking processes. When irradiated by $\mathrm{UV}, \mathrm{BP}$ was excited to the single state $\left(\mathrm{BP}^{\mathrm{S}}\right)$ and immediately relaxed to the stable triplet state $\left(\mathrm{BP}^{\mathrm{T}}\right)$ through intersystem crossing (ISC), then $\mathrm{BP}^{\mathrm{T}}$ abstracted hydrogen from the surface of the polymeric substrate the hydrogen donor. Thus the surface free radicals and semibenzopinacol free radicals were generated.

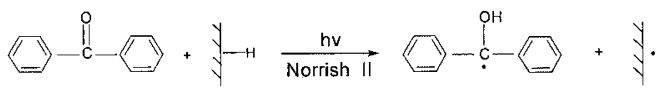

Due to large bulk and $\pi$-conjugate effect, the semibenzopinacol free radicals were not active. However, the surface free radicals were more active by far, so that the photografting polymerization carried out smoothly, resulting in the highest grafting efficiency.

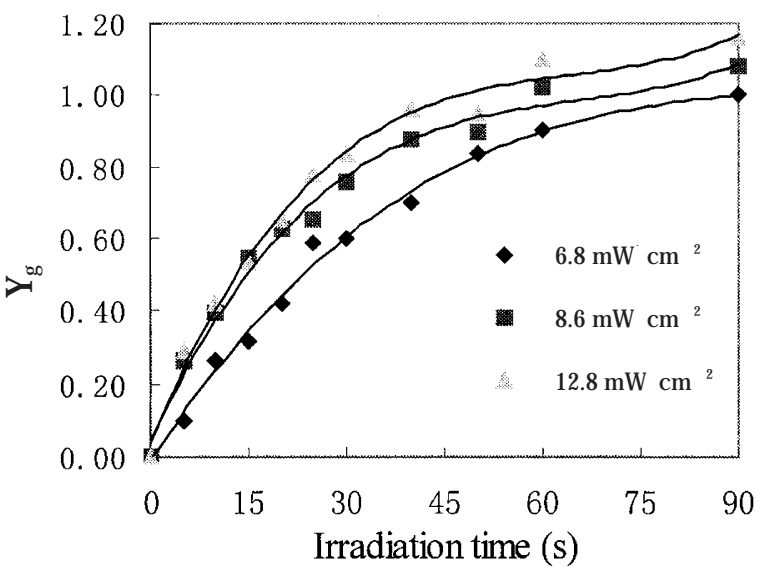

Figure 3. Effect of UV intensity on the grafting yield of the photografting of MAH/BVE. UV intensity was altered by varying the distance from the lamp to the sample. Molar ratio of MAH to BVE, 1:1; total monomer concentration, $4 \mathrm{~mol} \mathrm{~L}^{-1}$; photoinitiator, $\mathrm{BP}, 0.05 \mathrm{~mol} \mathrm{~L}^{-1}$; solvent, acetone; volume of reaction solution, $5 \mu \mathrm{L}$; reaction temperature, $50^{\circ} \mathrm{C}$.

As for ITX, it can also undergo the hydrogen abstraction reaction, but the intermolecular rearrangement occurs at the same time. ${ }^{25}$
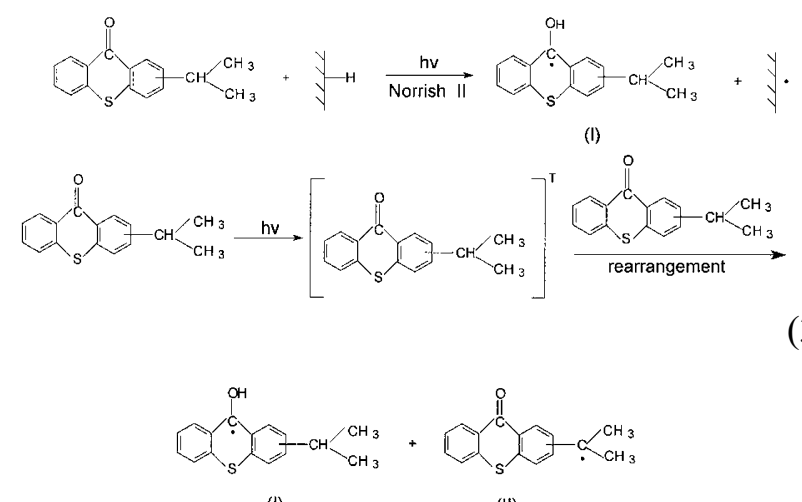

The free radicals (I) are not active while the free radicals (II) are a little more active, so the homopolymerization arose to some extent in this system. Thus the photografting ability of ITX is less than BP in some sort.

In addition, it should be pointed out that the monomer MAH could also act as a photoinitiator and participated in the initiation process, the mechanism of which will be discussed in detail in the latter article.

UV Intensity and Its Wavelength. The effect of UV lies in two aspects involving the intensity and the wavelength. According to the general principles of the photopolymerization, ${ }^{26}$ the rate of initiation reaction is proportional to UV intensity and the rate of polymerization is proportional to the square root of UV intensity. So the high UV intensity was expected to be favorable to the photografting polymerization, and the experimental results have confirmed the assumption, as shown in Figure 3. 
Table II. Photografting performance of MAH/BVE with and without far $\mathrm{UV}^{*}$

\begin{tabular}{|c|c|c|c|c|c|c|c|c|c|c|c|c|}
\hline \multirow{3}{*}{$t(\mathrm{sec})$} & \multicolumn{6}{|c|}{$C_{\mathrm{p}}(\%)$} & \multicolumn{6}{|c|}{$Y_{\mathrm{g}}(\%)$} \\
\hline & \multicolumn{2}{|c|}{ BP } & \multicolumn{2}{|c|}{ ITX } & \multicolumn{2}{|c|}{ BDK } & \multicolumn{2}{|c|}{ BP } & \multicolumn{2}{|c|}{ ITX } & \multicolumn{2}{|c|}{ BDK } \\
\hline & $\overline{+^{\mathrm{a}}}$ & $\overline{-^{b}}$ & + & - & + & - & $\overline{+}$ & - & + & - & + & - \\
\hline 10 & 33.8 & 1.0 & 54.5 & 49.0 & 60.0 & 13.1 & 0.39 & 0 & 0.31 & 0 & 0.20 & 0 \\
\hline 20 & 59.6 & 2.5 & 70.4 & 65.2 & 80.2 & 15.2 & 0.62 & 0 & 0.47 & 0 & 0.30 & 0 \\
\hline 30 & 70.0 & 3.0 & 75.3 & 68.7 & 87.2 & 20.7 & 0.75 & 0 & 0.52 & 0.01 & 0.37 & 0 \\
\hline 40 & 76.1 & 3.5 & 83.6 & 70.4 & 89.4 & 22.2 & 0.83 & 0 & 0.57 & 0.02 & 0.43 & 0 \\
\hline 50 & 81.8 & 4.5 & 85.6 & 72.2 & 94.0 & 24.8 & 0.89 & 0 & 0.65 & 0.03 & 0.53 & 0 \\
\hline 60 & 83.2 & 5.6 & 88.0 & 75.3 & 94.9 & 27.2 & 1.01 & 0 & 0.71 & 0.05 & 0.56 & 0 \\
\hline 90 & 90.3 & 6.1 & 93.2 & 79.6 & 97.8 & 29.7 & 1.15 & 0 & 0.79 & 0.06 & 0.68 & 0 \\
\hline
\end{tabular}

${ }^{*}$ Molar ratio of MAH to BVE, 1:1; total concentration, $4 \mathrm{~mol} \mathrm{~L}^{-1}$; concentration of photoinitiator, $0.05 \mathrm{~mol} \mathrm{~L}^{-1}$; solvent, acetone; volume of reaction solution, $5 \mu \mathrm{L}$; reaction temperature, $60{ }^{\circ} \mathrm{C}$; UV intensity, $8600 \mu \mathrm{W} \mathrm{cm}{ }^{-2}$.

${ }^{\mathrm{a}}$ With far UV. ${ }^{\mathrm{b}}$ Without far UV.

As to the UV wavelength, it determines the energy of the photon according to the formula $E=h v$. Since various photoinitiators have different specific absorption band, it is very important to choose the appropriate UV wavelength for the photografting polymerization. Here a piece of PET film, which is known to cut off almost all the far UV irradiation (200-300 nm $)^{8}$, was used as a filter. The photografting performance of MAH/BVE with and without far UV is presented in Table II.

As shown in Table II, the values of $C_{\mathrm{p}}$ and $Y_{\mathrm{g}}$ of all these three photoinitiators were decreased remarkably when the far UV radiation was eliminated. As to $C_{\mathrm{p}}$, the extents of the decline were different among the various photoinitiators. To speak in detail, $C_{\mathrm{p}}$ of $\mathrm{BP}$ decreased the most, because its major absorption band was $254 \mathrm{~nm} ; C_{\mathrm{p}}$ of BDK decreased a little less, because it has some sort of absorption at $340 \mathrm{~nm}$ besides the major absorption band $246 \mathrm{~nm}$; while $C_{\mathrm{p}}$ of ITX decreased the least in that it has not only major absorption at $260 \mathrm{~nm}$ but also some absorption at $385 \mathrm{~nm} .{ }^{27}$ As to $Y_{\mathrm{g}}$, it can be surprisingly seen that the values of $Y_{\mathrm{g}}$ all decreased close to 0 (no grafted polymer could be detected by gravimetric method) in the absence of far UV radiation, except that ITX had a little grafting yield after $30 \mathrm{~s}$ of the irradiation time. This significant result indicates that far UV radiation is favorable to this photografting system, which is consistent with our previous results. $^{8}$

It should be pointed out that the effective UV wavelength on the hydrogen abstraction reaction of BP was different from the common concept. In the most studies, ${ }^{4-7}$ the UV wavelength range used for the photografting was longer than $300 \mathrm{~nm}$ (usually $366 \mathrm{~nm}$ ), which corresponds to $n-\pi^{*}$ transition. Moreover, the traditional photografting was conducted with the vapor phase method and liquid phase method, and the irradiation time was usually as long as $60 \mathrm{~min}$, even $90 \mathrm{~min}$ sometimes, resulting in very high grafting yield. In the "FIP" operation, however, the fixed amount of reaction solution was deposited between two overlapping films, therefore the grafting reaction can be confined merely on the surface of the substrate, which facilitates to realize the rapid effective surface modification of the polymer substrates. Although the $\left(n, \pi^{*}\right)$ state of BP excited by near UV has higher oxidation ability, its extinction coefficient is much less $\left(e . g ., \varepsilon_{366 \mathrm{~nm}}=\right.$ $\left.70 \mathrm{~L} \mathrm{~mol}^{-1} \mathrm{~cm}^{-1}\right)$ than that at the $\left(\pi, \pi^{*}\right)$ state $\left(\varepsilon_{254 \mathrm{~nm}}=\right.$ $\left.1.7 \times 10^{4} \mathrm{~L} \mathrm{~mol}^{-1} \mathrm{~cm}^{-1}\right)$. So the photoreduction rate of $\mathrm{BP}$ at the $\left(\mathrm{n}, \pi^{*}\right)$ state is much slower than that at the $\left(\pi, \pi^{*}\right)$ state, accordingly resulting in the different photografting rates. In addition, we have found out that if near UV was used and the irradiation time was prolonged meanwhile, most monomer would perform homopolymerization rather than graft polymerization. In conclusion, we consider that far UV is favorable to this photografting system conducted with "FIP" method.

Total Monomer Concentration. The effects of the total concentration of the binary monomers MAH/BVE are illustrated in Figure 4.

Figure 4 shows that the grafting yield increased smoothly while the grafting efficiency decreased unexpectedly along with the increase of the monomer concentration. This phenomenon can be attributed to the fact that the photografting system is heterogeneous. That is, the photografting polymerization occurs merely at the liquid-solid interface between the liquid phase and the substrate, and the homopolymerization occurs in the liquid phase meanwhile. When the monomer concentration increased, the photografting polymerization and homopolymerization both speeded up though, the latter would increase more remarkably in that the amount of monomer and photoinitiator near the interface changed little while those in the liquid phase changed much. Consequently, the grafting efficiency (which was defined as $W_{\mathrm{g}} / W_{\mathrm{p}}$ ) declined inevitably. Nevertheless, in order to obtain high grafting 
Table III. Effects of various solvents on the photografting of MAH/BVE*

\begin{tabular}{|c|c|c|c|c|c|c|c|c|c|c|c|c|}
\hline \multirow{2}{*}{$t(\mathrm{sec})$} & \multicolumn{4}{|c|}{$C_{\mathrm{p}}(\%)$} & \multicolumn{4}{|c|}{$Y_{\mathrm{g}}(\%)$} & \multicolumn{4}{|c|}{$E_{\mathrm{g}}(\%)$} \\
\hline & $\overline{\mathrm{AC}}$ & EA & THF & DMF & $\overline{\mathrm{AC}}$ & EA & THF & DMF & $\overline{\mathrm{AC}}$ & EA & THF & DMF \\
\hline 10 & 33.8 & 30.3 & 62.6 & 23.2 & 0.39 & 0.26 & 0.22 & 0.01 & 58.3 & 43.2 & 17.7 & 1.3 \\
\hline 20 & 59.6 & 57.7 & 75.3 & 34.8 & 0.62 & 0.38 & 0.32 & 0.02 & 52.5 & 33.3 & 21.5 & 2.3 \\
\hline 30 & 66.2 & 68.7 & 77.8 & 37.4 & 0.75 & 0.55 & 0.38 & 0.04 & 57.3 & 40.5 & 24.7 & 5.3 \\
\hline 40 & 79.3 & 78.4 & 81.8 & 42.4 & 0.87 & 0.62 & 0.40 & 0.05 & 55.5 & 39.9 & 24.4 & 5.9 \\
\hline 50 & 81.8 & 82.3 & 86.9 & 52.5 & 0.89 & 0.64 & 0.43 & 0.07 & 54.9 & 39.2 & 25.0 & 6.7 \\
\hline 60 & 89.3 & 91.9 & 93.9 & 59.6 & 1.01 & 0.71 & 0.54 & 0.08 & 56.4 & 39.1 & 29.1 & 14.2 \\
\hline
\end{tabular}

${ }^{*}$ Molar ratio of MAH to BVE, $1: 1$; total concentration, $4 \mathrm{~mol} \mathrm{~L}^{-1}$; photoinitiator, $\mathrm{BP}, 0.05 \mathrm{~mol} \mathrm{~L}^{-1}$; volume of reaction solution, $5 \mu \mathrm{L}$; reaction temperature, $60^{\circ} \mathrm{C}$; UV intensity, $8600 \mu \mathrm{W} \mathrm{cm}{ }^{-2}$.

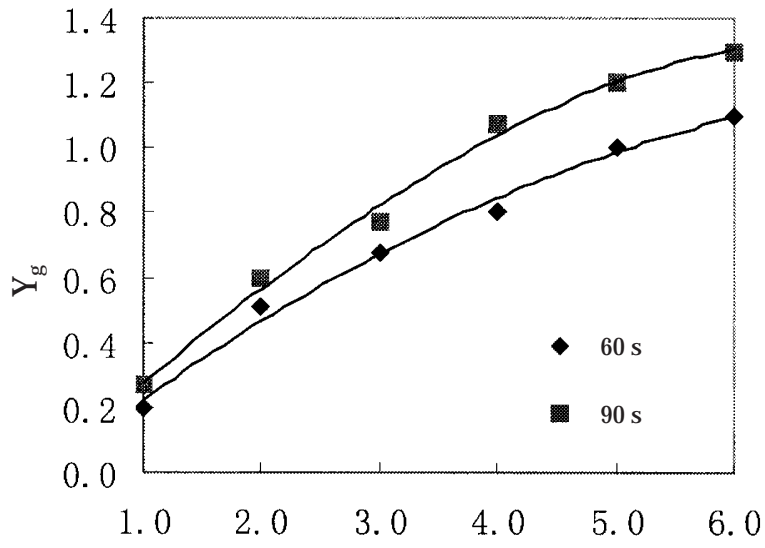

Total monomer concentration $\left(\mathrm{mol} \mathrm{L}^{-1}\right)$

(A)

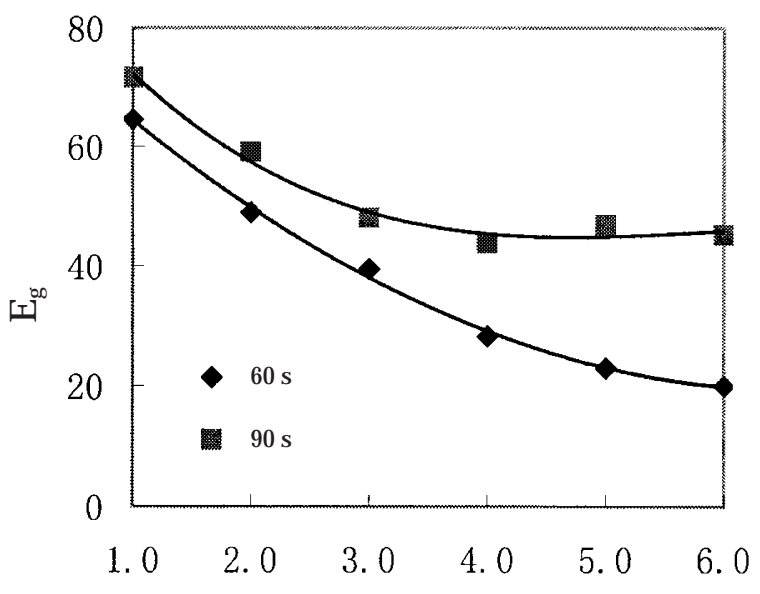

Total monomer concentration $\left(\mathrm{mol} \mathrm{L}^{-1}\right)$

(B)

Figure 4. Effect of the total concentration of MAH/BVE on the grafting yield (A) and grafting efficiency (B). Molar ratio of MAH to BVE, $1: 1$; photoinitiator, $\mathrm{BP}, 0.05 \mathrm{~mol} \mathrm{~L}^{-1}$; solvent, acetone; volume of reaction solution, $5 \mu \mathrm{L}$; reaction temperature, $60^{\circ} \mathrm{C}$; $\mathrm{UV}$ intensity, $6900 \mu \mathrm{W} \mathrm{cm}{ }^{-2}$.

yield within short irradiation time, it is necessary to increase the monomer concentration to some extent.

Solvents. The solvent in the heterogeneous photografting system not only dissolves the monomer and photoinitiator, but also carries them to the liquid-solid interface, so the affinity between the solvent and the substrate was supposed to be a crucial factor affecting the photografting. Moreover, some certain solvents used in the photografting system may act on the monomer or the UV radiation. In this study, some common solvents such as AC, EA, THF, DMF, were investigated and the results are summarized in Table III.

As observed in Table III, the effects of the various solvents on the photografting of MAH/BVE were different. 1) AC and EA had the similar positive effect on the photografting, because they are both affinitive towards the substrate-the solubility parameter $(\delta)$ of PP, AC, EA are $16.6\left(\mathrm{~J} \mathrm{~m}^{-3}\right)^{1 / 2}, 20.09\left(\mathrm{~J} \mathrm{~m}^{-3}\right)^{1 / 2}$, $18.7\left(\mathrm{~J} \mathrm{~m}^{-3}\right)^{1 / 2}$ respectively. ${ }^{28}$ When the reaction system was soaked in the fine solvent, the monomer and photoinitiator could migrate to the substrate smoothly, moreover, the mobility of the surface free radicals and grafting chain free radicals increased meanwhile. As a result, the photografting polymerization performed efficiently. In addition, it can be also found that the $Y_{\mathrm{g}}$ of AC was higher than that of EA, which accordingly resulted in the higher $E_{\mathrm{g}}$ value. The reason may lie in the fact that $\mathrm{AC}$ can act as photoinitiator as well under UV irradiation and therefore can initiate the grating polymerization. $\left.{ }^{5} 2\right)$ THF $\left(\delta=18.9\left(\mathrm{~J} \mathrm{~m}^{-3}\right)^{1 / 2}\right.$ is also affinitive towards the substrate, but the $C_{\mathrm{p}}$ was noticeably high while $Y_{\mathrm{g}}$ and $E_{\mathrm{g}}$ were low. This is because THF can form CTC with MAH as well as BVE does, which subsequently initiated the homopolymerization in the liquid phase. ${ }^{29}$ As a result, the grating polymerization was severely inhibited. 3) As for $\operatorname{DMF}(\delta=$ $24.6\left(\mathrm{~J} \mathrm{~m}^{-3}\right)^{1 / 2}$, it has very bad affinity towards the substrate, so it was very difficult for the monomer and photoinitiator to migrate to the substrate, leading to the low grafting efficiency.

\section{FT-IR Spectra}

The FT-IR spectra in Figure 5 show that some specific vibration absorption appeared in the grafted PP film compared with that of the blank PP film. The absorption at $1785 \mathrm{~cm}^{-1}$ and $1860 \mathrm{~cm}^{-1}$ indicated the existence of the anhydride group, and the absorption at $1102 \mathrm{~cm}^{-1}$ indicated the existence of the ether bond 


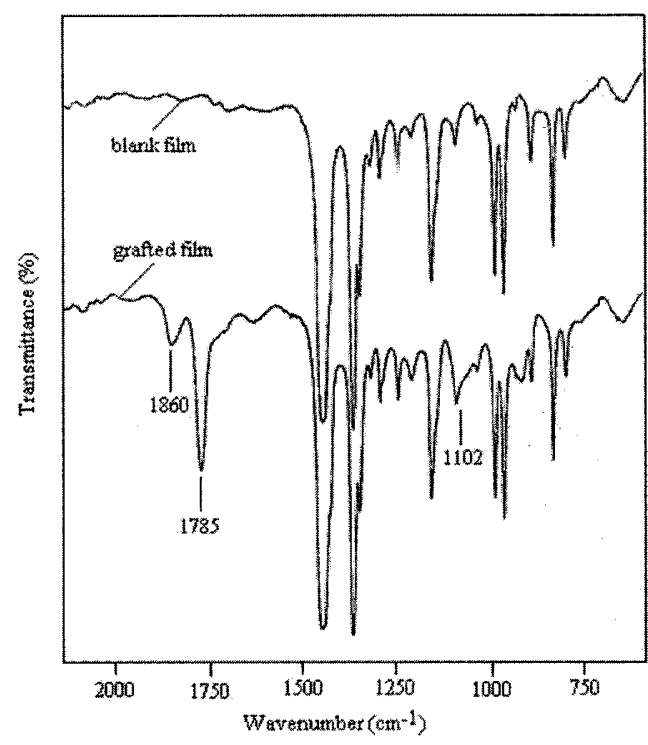

Figure 5. FT-IR Spectra of the blank PP film and grafted PP film. The grafting yield of the grafted film was $1.35 \%$, which was prepared under such conditions: molar ratio of MAH to BVE, 1:1; total monomer concentration, $4 \mathrm{~mol} \mathrm{~L}^{-1}$; photoinitiator, $\mathrm{BP}, 0.05 \mathrm{~mol} \mathrm{~L}^{-1}$; solvent, acetone; volume of reaction solution, $5 \mu \mathrm{L}$; reaction temperature, $60{ }^{\circ} \mathrm{C}$; UV intensity, $7600 \mu \mathrm{W} \mathrm{cm}{ }^{-2}$; irradiation time, $60 \mathrm{~s}$.

$(-\mathrm{CO}-)$, which confirmed that the binary monomers $\mathrm{MAH} / \mathrm{BVE}$ had been successfully grafted onto the PP film.

\section{Contact Angle against Water}

The main purpose of the photografting polymerization is to modify the surface property of the polymeric materials, especially to increase the surface polarity and therefore improve the hydrophilicity. In this study, the surface contact angles of the modified surface with various grafting yields were measured. The results are shown in Figure 6.

It can be obviously seen from Figure 6 that the contact angle decreased along with the increase of the grafting yield, which indicated that the photografting of $\mathrm{MAH} / \mathrm{BVE}$ is an effective and efficient method to improve the surface hydrophilicity of the polymeric materials. Furthermore, it can be found out that the contact angle of the grafted films with hydrolysis decreased more remarkably than that of the grafted films without hydrolysis. This is because each anhydride group in MAH can be hydrolyzed into two carboxyl groups, which increased the density of the polar groups on the surface of the grafted polymer. The reaction is schematically expressed as follows.

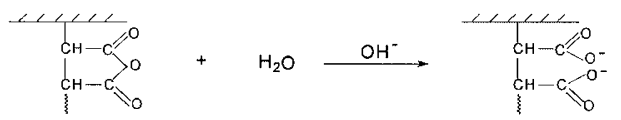

When the grafting yield exceeded $0.90 \%$, the decrease of the contact angle slowed down, because the

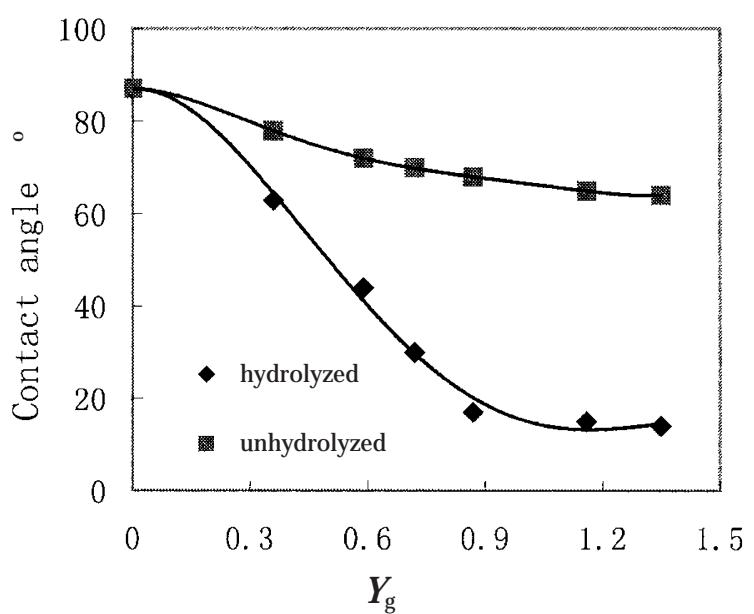

Figure 6. Effect of the grafting yield on the contact angle against water. The grafted films were prepared under such conditions: molar ratio of MAH to BVE, $1: 1$; total monomer concentration, $4 \mathrm{~mol} \mathrm{~L}^{-1}$; photoinitiator, $\mathrm{BP}, 0.05 \mathrm{~mol} \mathrm{~L}^{-1}$; solvent, acetone; volume of reaction solution, $5 \mu \mathrm{L}$; reaction temperature, $60^{\circ} \mathrm{C}$; UV intensity, $7600 \mu \mathrm{W} \mathrm{cm}^{-2}$; the irradiation time was various.

film surface had been entirely covered with a layer of the grafted chains.

\section{CONCLUSIONS}

(1) The surface photografting polymerization of MAH/BVE is a rapid effective approach to modify the surface property of the polymeric materials; the contact angle of the modified surface decreases remarkably within short irradiation time.

(2) By means of introducing the electron donor monomer $n$-BVE, the graft polymerization of MAH can be largely promoted; the grafting efficiency reaches the maximum when the molar ratio of MAH to BVE is 1:1. (3) The hydrogen abstractable photoinitiator BP has the highest grafting efficiency; far UV (200-300 nm) radiation is favorable to the photografting polymerization and high UV intensity can accelerate this process; in addition, the solvents with good affinity towards the substrate are favorable to increase the grafting efficiency.

Acknowledgment. This research has been supported by Special Funds for Major State Basic Research Projects (G1999064800) and the Chinese Outstanding Youth Foundation (20025415), which are gratefully acknowledged.

\section{REFERENCES}

1. M. H. Rao and K. N. Rao, J. Appl. Polym. Sci. 33, 2707 (1987).

2. H. K. Yasuda, in "Polymer Wear and Its Control", L.-H. Lee, 
Ed., ACS Symp. Ser, American Chemical Society, Washington, D.C., 1985, vol. 287, p 89.

3. C. L. Liu and Q. Wang, Polym. Mater. Sci. Eng. 15, 85 (1999).

4. H. Kubota and Y. Ogiwara, J. Polym. Sci., Part C: Polym. Lett. Ed., 19, 457 (1981).

5. K. Allmer, A. Hult, and B. Rånby, J. Polym. Sci., Part A: Polym. chem., 26, 2099 (1988).

6. S. Tazuke and H. Kimura, Makromol. Chem., 179, 2613 (1978).

7. B. Rånby and Z. M. Gao, Polym. Prepr., (Am. Chem. Soc., Div. Polm. Chem.), 27, 38 (1986).

8. W. T. Yang and B. Rånby, Polym. Bull., 37, 89 (1996).

9. W. T. Yang and B. Rånby, Eur. Polym. J., 35, 1557 (1999).

10. H. Kubota, Y. Murata, and Y. Ogiwara, J. Polym. Sci., Polym. Chem. Ed., 11, 485 (1973).

11. O. N. Tretinnikov and Y. Ikada, Macromolecules, 30, 1086 (1997).

12. J. I. Martin and Z. Wang, J. Phys. Chem., 99, 2833 (1995).

13. H. Kubota, N. Koike, and Y. Ogiwara, J. Polym. Sci., Polym. Lett. Ed., 25, 273 (1987).

14. P. Y. Zhang and B. Rånby, J. Appl. Polym. Sci., 40, 1647 (1990).

15. W. T. Yang and B. Rånby, Macromolecules, 29, 3308 (1996).

16. H. Kubota and Y. Ogiwara, J. Appl. Polym. Sci., 43, 1001 (1991).

17. W. T. Yang and B. Rånby, J. Appl. Polym. Sci., 62, 545 (1996).
18. K. Allmer, A. Hult, and B. Rånby, Eur. Polym. J., 27, 1641 (1989).

19. J. P. Deng and W. T. Yang, J. Polym. Sci., Part A: Polym. Chem., 39, 3246 (2001).

20. H. Kubota, Y. Nobuyuki, and Y. Ogiwara, J. Appl. Polym. Sci., 39, 1231 (1990).

21. H. Kubota and M. Koyama, J. Appl. Polym. Sci., 63, 1635 (1997).

22. P. D. Bartlett and K. Nozaki, J. Am. Chem. Soc., 68, 1495 (1946).

23. J. P. Deng, W. T. Yang, and B. Rånby. J. Appl. Polym. Sci., 77, $1513(2000)$.

24. H. J. Hageman, in "Eldevier Applied Science", London and New York, 1989, p 1.

25. W. T. Yang, M. Z. Yin, and Y. F. Sun, Chin. J. Polym. Sci., 5, 431 (2000).

26. Z. R. Pan, in "Polymer Chemistry", Chemical Industry Press, Beijing, China, 1997, p 40.

27. C. G. Roffey, in "Photopolymerization of Surface Coatings", John Wiley \& Sons Ltd., Chichester, 1982, chapt.3.

28. Q. C. Gu, S. C. Lou, and Q. P. Dai, in "Chemistry Handbook", Jiangsu Science Technology Press, Nanjing, China, 1979, pp $5-26$.

29. A. Torres and F. Castano. Makromol. Chem., 179, 2653 (1978). 